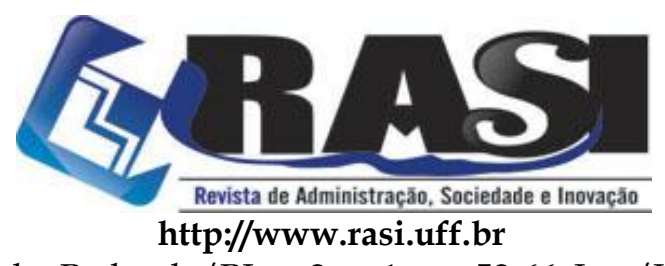

RASI, Volta Redonda/RJ, v. 2, n. 1, pp. 52-66, Jan./Jun. 2016

\title{
Representação Social da Liderança: análise em uma Organização da Administração Pública Federal
}

Marcelo M. Abdalla, Carine Fernandes Botelho, Patrícia N. Brito, Yury Vasconcellos da Silva

\begin{abstract}
RESUMO
Com a evolução dos modelos de Gestão Pública, as questões sociais ganharam nova dimensão nas políticas. Devido à necessidade de se desenvolver potenciais humanos nas diversas atividades, a liderança tornou-se uma importante ferramenta para o planejamento de ações e consecução de diversos objetivos, tornando-se relevante e fundamental apreender como este conceito faz parte e integra a vida dos agentes públicos. Dessa maneira, o presente trabalho foi desenvolvido com o objetivo de se alcançar uma compreensão da Liderança em uma Organização da Administração Pública Federal, por meio da utilização da teoria da Representação Social, realizada junto a uma amostra pertencente a uma Unidade Militar que integra a Administração Pública Federal. Os participantes foram integrantes pertencentes aos diversos quadros da mesma e houve aplicação de entrevistas não estruturadas, fazendo-se uso da teoria da Associação Livre de Palavras, na aplicação das entrevistas, e da Análise de Conteúdo, na interpretação dos dados. Por meio desse levantamento, objetivou-se uma verdadeira compreensão da Representação Social da Liderança junto a esses agentes. Com os resultados obtidos, foi possível concluir pela necessidade da utilização da liderança nas relações intersociais na Unidade estudada e sua consequente falha na Gestão Pública, algo relevante e significativo para o planejamento e gestão na Organização pesquisada, podendo contribuir para modificações fundamentais na estrutura da cultura organizacional, além de apresentar a necessidade dessa ferramenta na Administração Pública como um todo, tanto nas questões atinentes à gestão, quanto no desenvolvimento desse campo científico de conhecimento.
\end{abstract}

PALAVRAS-CHAVE: Liderança, Representação Social, Gestão Pública.

\section{ABSTRACT}

With the development of models of public management, social issues have gained new dimension in policy. Due to the necessity of being developed human potentials in the several activities, leadership has become an important tool for projection actions and achieve several goals, becoming a relevant and fundamental grasp how this concept is part and integrates the lives of public officials. Thus, this study was developed with the aim of achieving an understanding of Leadership in an Organization of the Federal Public Administration, through the use of the theory of Social Representation, conducted with a sample belonging to a Military Unit that integrates Management Federal Public. Participants were members belonging to different frames of the same and there was no application of structured interviews, making use of the theory of Words of Free Association, the application of interviews, and Content Analysis, interpretation of data. Through this survey, we aimed to be a reliable understanding of Social Leadership Representation to these agents. With the results, we concluded the need of the use of lead in intersocial relations in the Unit studied and its consequent failure in Public Management, something relevant and meaningful planning and management in the research organization, contributing to fundamental changes in crop structure organizational, and present the need for this tool in the Public Administration as a whole, both in matters related to the management, and in the development of this scientific field of knowledge.

KEYWORDS: Leadership, Social Representation, Public Management.

\begin{tabular}{c}
\hline $\begin{array}{l}\text { Universidade } \\
\text { Federal } \\
\text { R. Deseminense } \\
\text { 27213-415 - Volta Redonda, RJ - Brasil } \\
\text { www.uff.br }\end{array}$ \\
\hline $\begin{array}{c}\text { Copyright (C) 2016 RASI. Todos os direitos, até mesmo de tradução, são reservados. É } \\
\text { permitido citar parte de artigos sem autorização prévia, desde que seja identificada a fonte. }\end{array}$ \\
\hline
\end{tabular}




\section{Desenvolvimento de um plano de gerenciamento de resíduos de serviços de saúde,} para unidade de suporte de pacientes portadores do HIV

\section{Introdução}

A liderança é um conceito abordado pela Psicologia Organizacional e que há décadas vem sendo estudada e muito relacionada ao ambiente de trabalho (Schette 2005). Tal fato se dá pelas modificações que proporciona por meio da influência direta sobre as pessoas, na qualidade de vida no trabalho, além da capacidade de influenciar diversos processos organizacionais (Freitas 2013).

Realizar um estudo sobre a liderança, busca a compreensão de uma temática comum nas organizações privadas, entretanto, discreta no meio público. Sendo relevante sua inserção na dinâmica da administração pública, devido à sua influência no comprometimento organizacional (Fonsêca 2011).

A importância atribuída à liderança pelas organizações privadas contribui em diversos aspectos com o clima organizacional. O que remete a indagação do porquê somente a partir do movimento da chamada Nova Administração Pública que o termo liderança passou a receber notoriedade no meio público (Oliveira, Sant'anna y Vaz 2010).

Dessa maneira, há uma necessidade atual de compreender a liderança no ambiente estatal. Sendo objetivo do presente estudo um levantamento junto a uma amostra, utilizando-se da Representação Social. Tal conceito desenvolvido por Moscovici (2012) que trata do levantamento do pensamento comum de determinado assunto, junto aos participantes da pesquisa e que influencia a lógica sistemática da ciência, que no caso é a representação social dos integrantes do ambiente público sobre o assunto abordado: Liderança na Administração Pública.

\section{Referencial Teórico}

\subsection{Liderança}

A liderança contribui para o desenvolvimento de diversas estratégias, assim como na melhoria e qualidade dos serviços públicos (Freitas 2013). Para Niemeyer y Cavazotte (2016) a liderança ética promove ganhos de produtividade e comportamentos de cidadania entre funcionários, pelo fato dos liderados ao perceberem seus líderes mais éticos, tendem a desenvolver comportamentos de cidadania organizacional.

Segundo Araújo y Zuppano (2016) a liderança é um conceito complexo, multifacetado, cujo estudo remonta a muitos anos, objetivando a busca do desenvolvimento de processos e líderes mais eficientes. Brant (2012) apresenta a existência de diversas abordagens no estudo da liderança e que apesar de muitas pesquisas sobre o tema, não se tem uma clara definição sobre este conceito.

Gonçalves (2014) defende a existência de diversos modelos conceituais sobre liderança, contudo, os pesquisadores concordam ao reconhecer que este conceito trata de um processo de influência sobre um determinado grupo de pessoas. Ainda, o autor aponta que a primeira sistematização de estudos sobre a liderança veio com a teoria dos traços, que verifica as qualidades inatas da pessoa no contexto da liderança. Cunha y Silva (2010) apontam que nesta teoria características como traços físicos, intelectuais e sociais voltados a uma tarefa são os determinantes de um líder. 
Na compreensão da teoria dos traços existe um padrão básico de personalidade dos líderes e que consequentemente revelariam os mesmos traços em quaisquer situações (Andrade 2013).

Segundo Bergamini (1994) a teoria dos traços começou nos anos 40 e por ser muito reducionista, ao verificar somente fatores inatos, iniciou-se nos anos 50 análises dos comportamentos das pessoas consideradas líderes, de forma a sistematizar e compreender suas ações e possibilidades de treinar pessoas comuns ao exercício da liderança.

Portanto, segundo Arengheri (2014) seguiu-se a teoria comportamental a qual Andrade (2013) afirma que os estudos da liderança se voltavam para a observação e tentativa de compreensão do comportamento e atitudes das pessoas consideradas socialmente líderes, havendo duas grandes categorias de orientação de comportamento: àquela voltada para as tarefas e cumprimento de objetivos e a outra voltada para as pessoas ou relacionamentos, havendo nesta uma preocupação com o bem-estar alheio.

Com o desenvolvimento dos estudos, surgiram-se as abordagens situacionais. Conforme Oliveira y Chamarelli (2011) nesta teoria os líderes devem desenvolver suas habilidades e percepções de acordo com as mais variadas situações, diagnosticando nas equipes fatores que norteiem seus comportamentos, ou seja, adaptando e agindo de acordo com as variáveis situacionais, havendo maior flexibilidade em suas ações de liderança, de acordo com as contingências.

A partir da década de 1980 surgiram novas abordagens, como a Teoria da Liderança Carismática, Teoria de Liderança Transformacional, Transacional e Laissezfaire (Benevides 2010). Também a Teoria da Liderança Baseada em Princípios (Cunha y Silva 2010). Liderança Estratégica, Visionária e Gerencial (Rowe 2002). Teoria da troca entre líderes e membros - LMX (Leader Member Exchange Theory) que estuda as variadas relações entre líderes e liderados e seus consequentes resultados no processo organizacional e que, além disso, surgiram diversos estudos em que os pesquisadores adotam múltiplas e diversificadas abordagens para compreender o fenômeno da liderança em determinado contexto (Brant 2012).

É importante destacar que apesar da diversidade de estudos e abordagens, não existe uma forma única e concisa de liderar e que não é garantida a eficiência dessa ação em todas as situações (Benevides 2010).

Pfeffer (2015) critica o caráter normativo das diferentes abordagens, por apontarem poucas evidências que sustentem as prescrições, a apresentação de características preconizadas como ideias para a liderança, não sendo, necessariamente, pertinente a um determinado contexto. Segundo Vils y Rodrigues (2016) a indústria da liderança, aparentemente se apresenta em um mundo paralelo e utópico, com a colocação de qualidades desejadas em um líder que definitivamente são diferentes daquelas valorizadas no mundo corporativo.

Diante do exposto, o que torna importante às ações de liderança é a possibilidade de vencer as situações de instabilidade e manter o potencial motivacional de sua equipe (Cunha y Silva 2010). Dessa maneira, não se pretende seguir alguma abordagem específica, tendo em vista que o objetivo da pesquisa é conhecer a representação da liderança no meio público e não propriamente testar a importância dessa diversidade. 


\subsection{Gestão pública}

A liderança, pela capacidade de influenciar o potencial humano na consecução de objetivos e resultados, torna-se indispensável como ferramenta integrante no processo de construção e desenvolvimento dos diversos modelos de gestão pública.

A abordagem evolucionista aponta no desenvolvimento histórico da administração pública uma sequência de categorias como um processo de modernização (Bresser-Pereira, 2001). Apresentando modelos de gestão que foram desenvolvidos durante o transcorrer histórico do país e que foram se aperfeiçoando, a começar pelo patrimonialista, seguindo-se para o burocrático, o gerencialista e, em fase de implantação, o societal (Drumond, Silveira y Silva 2014). Segundo os autores, este último é um conceito em construção que trabalha com o societalismo, transparência e governança pública, com participação e investimento social. Com este novo modelo, portanto, abrem-se maiores possibilidades de participações em políticas públicas na área social, com consequente consideração e relevância da liderança nesse contexto.

Apesar de a perspectiva evolucionista deixar de reconhecer a permanência e a convivência entre novas e velhas formas (Costa y Costa 2016), está sendo apresentada não com o objetivo de caracterizar e conceituar, mas de uma forma de organização didática do presente trabalho, não tratando o tema com simplificação, haja vista a gama de fatores e transformações entre os períodos, ilustrando características presentes na abordagem social quanto aos seus pressupostos teórico-metodológico nas políticas públicas.

Segundo Costa y Costa (2016) com o surgimento da chamada nova história na Administração Pública houve maior interação com as ciências sociais e humanas. Dessa maneira, a gestão social ganha contornos mais nítidos nas fissuras do gerencialismo (Freitas, Freitas \& Ferreira 2016), sendo a gestão social uma abordagem de gestão da Administração Societal (Tenório 1998; Tenório 2005; Oliveira, Pereira 2014).

Uma gestão pública mais participativa e democrática entre a população e o Estado se refere à gestão social como projeto político (Freitas, Freitas \& Ferreira 2016). Dessa forma, o tema da inserção da participação popular na gestão pública é o cerne da mobilização societal (Paula 2005). Com isso, administração pública societal viabiliza relações simétricas entre Estado e sociedade, incorporando princípios da participação e deliberação coletiva (Oliveira, Pereira, 2014).

Segundo Ceneviva y Farah (2012) existem instrumentos de gestão em que acontecem diversas avaliações de políticas públicas e programas governamentais, objetivando-se determinar ações relevantes, resultados obtidos, fiscalização na prestação de contas e desempenho, avaliando-se com isso, a política realizada. Para esses autores as tendências recentes na avaliação de programas e políticas públicas, incluem a questão da efetividade, eficiência, da accountability e do desempenho. Havendo diversos fatores que podem influenciar nesses resultados, como o comportamento humano e organizacional.

Em relação ao comportamento humano, a gestão societal objetiva modificar o que foi apontado por Carbone (2000) ao expor que se valoriza no homem do setor público brasileiro a sua capacidade de conciliar interesses, apaziguar conflitos e aparentar aquilo que não é em verdade, distanciando-se de atributos dinâmicos como o empreendedorismo, inovação, ousadia e competência técnica.

Dessa maneira, a liderança deve ser incluída como ferramenta integrante no processo de gestão. Apesar disso, Vieira y Costa (2013) apontam que no contexto 
público este conceito é pouco pesquisado no Brasil, assim como apresentado por Martins y colaboradores (2010) ao pesquisarem a gestão de pessoas no setor público, em que de 174 (cento e setenta e quatro) pesquisas realizadas na área, somente 11 (onze) versaram sobre liderança e gerência. Rowe (2002) coloca que a liderança é muito restrita em diversas organizações, principalmente no meio estatal.

Objetivando aprofundar os conhecimentos sobre liderança no setor público, fazse importante conhecer como os integrantes desse meio pensam e agem sobre este conceito.

\subsection{Representações sociais}

Torna-se importante a compreensão da liderança em diversas situações e atividades profissionais, como mencionado por Athaydes, Becker, Cogo, Furlanetto y Nassar (2013) ao apresentarem sobre a questão mais importante para o líder de comunicação, além de outras em seu estudo.

Dessa forma, pela importância e necessidade de compreender a liderança e sendo um conceito subjetivo e de difícil mensuração, sua análise no contexto da Administração Pública Federal será realizada pela teoria das Representações Sociais, abordada pela Psicologia Social. Esta apresentada por Moscovici e inspirada na teoria de Durkheim sobre Representações Coletivas (Moscovici 2012). Santana, Reis, Reis y Tavares (2013) afirmam que a teoria das representações sociais tem se constituído como um valoroso suporte teórico nas pesquisas que objetivam investigar a percepção e imagem dos indivíduos sobre determinado objeto social.

Segundo Moscovici (2012) o fenômeno das representações sociais é tratado como o material subjetivo de determinado assunto, construído em uma relação humana, sendo gerado, transformado e devolvido ao mundo social. Em suma, aquilo que é produzido e projetado pelo pensamento comum e que influencia a lógica sistemática da ciência.

A representação social é caracterizada pelo conjunto de saberes e práticas constituídas de imagens, pressupostos culturais e históricos, conhecimentos prévios, expressos por meio da linguagem e pela interação social entre o individuo e a sociedade (Azevedo, Walber, Schujmann y Garay 2012). O saber construído a partir do senso comum seria consequência das inter-relações sociais e explicações originárias do cotidiano (Andrade, Muniz y Silva 2010).

A representação social se refere a um conteúdo mental conscientemente compartilhado com indivíduos de um grupo ao qual se relaciona a um processo público de criação, modificação, elaboração e difusão de conhecimentos (Natividade y Camargo 2012). Para Carvalho y Souza (2012) os fatores culturais e as diferentes formas de vida influenciam, em demasia, na escolha dos elementos que aparecem como estruturadores da representação.

Segundo Carvalho y Souza (2012) as representações sociais como teoria do senso comum, pode ser um fenômeno em grupo quando os elementos constituintes são partilhados entre seus membros. O que faz com que tal grupo passe a se caracterizar por tais representações, em razão do grau de adesão aos tipos de opiniões e são ancoradas coletivamente, apesar das diferenças individuais.

Para Jodelet (2009) a representação social tem origem nas esferas subjetivas, intersubjetivas e transubjetivas dos sujeitos. Segundo Ferreira, Santos y Rosso (2016) a esfera subjetiva está relacionada ao modo como cada indivíduo se apropria e reconstrói 
as representações. Para os autores a esfera intersubjetiva se relaciona ao contexto social constituído do sujeito e a esfera transubjetiva perpassa as outras esferas, assim, a representação social é afetada pelas condições ideológicas relacionadas ao contexto cultural de uma sociedade, seu conjunto de valores, normas e modelos transmitidos.

Jodelet (2001) afirma que tais fenômenos observáveis devem ser tratados como trabalho científico. Conforme Lemos, Costa y Lima (2013: 54) "[...] a atividade representativa constitui um processo psicossocial que permite tornar familiar e presente no universo interior do indivíduo um objeto que está distante, atribuindo-lhe significados compartilhados no grupo".

Com o desenvolvimento das pesquisas em representações sociais, estruturaramse três abordagens teóricas principais: a processual liderada por Jodelet, a estrutural, liderada por Abric e a societal, liderada por Doise (Almeida 2009).

Para a presente pesquisa, serão utilizados os procedimentos metodológicos de acordo com o contexto teórico trazido por Moscovici e complementado por Jodelet, em que o processo de representação é construído por meio da ancoragem, que é tornar comum, em um contexto familiar determinado conceito, classificando-o e comparandoo com outros paradigmas; e por meio da objetivação que é transformar o conceito abstrato em algo concreto (Moscovici 2012).

\section{Procedimento Metodológico}

\subsection{Classificação metodológica}

Segundo Silva y Menezes (2005) uma pesquisa, quanto à natureza pode ser classificada em básica ou aplicada, nesta última são produzidos conhecimentos práticos para aplicação e solução de problemas específicos. Com isso, a natureza da presente pesquisa é aplicada, justamente pela prática junto aos participantes, consequentemente a construção de novos conhecimentos. A partir daí, uma nova compreensão teórica e contribuições às pesquisas futuras.

Conforme apontam Pope y Mays (2009) a pesquisa qualitativa está relacionada com a busca de significados que as pessoas atribuem às suas experiências em seu universo social e o modo como compreendem o mundo. Portanto, em relação à forma de abordagem do problema, a pesquisa desenvolve-se como qualitativa, em que são analisados e verificados o conteúdo das respostas dos participantes, sendo este colocado de maneira descritiva e analisado o fenômeno da representação social da liderança, a partir dos integrantes da amostra pesquisada, embora, apresente nuances de uma perspectiva quantitativa, já que emprega uma vertente mais estruturada da Análise de Conteúdo.

Quanto aos objetivos trata-se de pesquisa exploratória, que segundo Gil (2007) busca-se maior conhecimento sobre algum assunto ao explorar a realidade. Assim, objetiva-se à descoberta do fenômeno da representação social do tema em questão, dessa forma, contribuindo à elucidação de novos conhecimentos sociais para o meio científico. Seguindo, os procedimentos técnicos desenvolvem-se por meio de levantamentos, classificados por Gil (2007) como um procedimento para coleta de dados. No entanto, o trabalho por ser de forma qualitativa não se fecha a simples apuração de informações, tratando-se de uma atividade de apreensão do fenômeno estudado, pela observação dos comportamentos e por meio da análise dos conteúdos respondidos pelos participantes. Fato este, em que a análise também não se restringe a 
uma simples apuração de respostas levantadas, como aponta o autor: "a análise de conteúdo é um conjunto de técnicas de análise das comunicações" (Bardin 1977: 31, grifo do autor).

\subsection{Procedimentos metodológicos}

Para Fadul, Silva y Silva (2012) o campo da administração pública compreende agentes e instituições que produzem conhecimento sobre a própria administração pública. Com isso, em relação à população de estudo, foi analisado o fenômeno em uma Organização Militar, pertencente às Forças Armadas do Brasil, entidade historicamente relacionada com atuação de lideranças em seu contexto, pela importância da influência na condução das pessoas, para a consecução dos objetivos e estratégias militares. Sendo esta Unidade Militar preservada sua identificação, devido fins éticos da pesquisa, a qual possuía população durante o estudo, composta por 59 (cinquenta e nove) graduados e oficiais de carreira, concursados, integrantes dessa unidade, que hierarquicamente estavam em um nível intermediário e que exerciam comando e liderança e também recebiam ordens superiores, ou seja, eram liderados e líderes no mesmo contexto.

Com isso, objetivando validade científica, a amostra pesquisada foi composta por treze participantes escolhidos aleatoriamente de uma Unidade Militar, sendo um número significativo, respeitando-se como critério metodológico a amostragem por saturação (Fontanella, Ricas y Turato 2008) em que se é possível apreender o fenômeno, tendo em vista a possibilidade de redundância e repetição de dados ao incluir demais participantes no fechamento amostral.

Sobre os procedimentos para coleta de dados, foi realizada junto aos participantes entrevista não estruturada, com três perguntas, objetivando aos mesmos responderem segundo aos seus próprios valores e significados, em ambiente externo ao seu meio de trabalho, de forma a possibilitar a menor influência às respostas dos mesmos. Ainda, foram observadas as diversas manifestações de comportamentos dos participantes durante as entrevistas, relevantes por não fazerem parte das respostas manifestas.

Com isso, os participantes foram orientados a responderem com o que lhe viessem à mente. Segundo Merten (1992) nesse tipo de associação pede-se ao sujeito que responda com a primeira palavra que lhe venha ao pensamento, em relação aos termos indutores apresentados na entrevista. Janczura (2005) coloca da mesma forma, ao abordar que na associação livre é apresentado um conjunto de palavras indutoras a uma amostra de indivíduos e espera-se que eles respondam com uma palavra que lhes vier à mente para cada uma das palavras da lista. Sendo assim, nessa adaptação ao estudo da técnica de associação de palavras, os participantes foram orientados a responder com a menor quantidade de palavras e do modo mais ágil, porém, com liberdade de respostas, objetivando a criação de associações livres, evitando-se construções verbais intelectualmente mais elaboradas que pudessem prejudicar a associação de ideias.

Quanto às perguntas, foram intencionalmente elaboradas, objetivando seguir o método da associação livre de palavras, de maneira a utilizar três termos indutores: Liderança, Liderança no Ambiente de Trabalho e Liderança na Administração Pública, para se levantar à Representação Social almejada, em que foram investigadas as frequências absolutas e relativas das respostas da amostra. 
Quanto à análise de dados foi realizada a análise de conteúdo, segundo Moraes (1999) trata-se de uma abordagem metodológica com características e possibilidades próprias. A análise de conteúdo é um conjunto de técnicas de análises de comunicações que pode ser utilizada no teste por associação de palavras, este que faz surgir dos participantes espontaneamente associações relativas às palavras indutoras. Dessa forma, as respostas foram devidamente tratadas pela análise de conteúdo, em que foram separadas palavras idênticas ou próximas a nível semântico, criando-se categorias, para a compreensão de sua significação e interpretação desses resultados obtidos (Bardin 1977).

\section{Resultados}

Foram realizadas entrevistas com treze participantes, nos meses de abril e maio de 2014 e obtido o consentimento por meio da autuação do Termo de Consentimento Livre e Esclarecido, em conformidade com as Resoluções nº 196/96 versão 2012 (2012) e n 466/2012 (2012), ambas do Conselho Nacional de Saúde, da República Federativa do Brasil que versam sobre a ética em pesquisa envolvendo seres humanos, dessa maneira garantindo o sigilo, o anonimato e demais prerrogativas éticas em relação aos participantes.

Foram gravadas em mídia eletrônica cada uma das entrevistas e devidamente transcritas, objetivando dessa maneira identificar ligações de palavras com proximidades entre si, as quais foram agrupadas e categorizadas por semelhança semântica. Apresentadas as frequências absolutas (fi) e relativas (fr\%) de cada categoria, organizadas em tabelas estatísticas para melhor visualização e compreensão. Estando inclusos, ainda, os termos principais verbalizados pelos participantes nas respostas, estes termos responsáveis pela criação das categorias.

Após a aplicação dos questionários são apresentadas tabelas elaboradas com os dados obtidos pela pesquisa, de forma a ilustrar os resultados obtidos, em termos estatísticos:

\section{TABELA 1 - Categorização das respostas dos participantes sobre a primeira pergunta}

Conteúdo da primeira pergunta pelo teste de associação de palavras: "Diga-me o que lhe vem à mente quando falamos sobre: Liderança"

\begin{tabular}{|c|c|c|c|}
\hline Categorias & Termos Respondidos pelos Entrevistados & $\mathbf{f i}$ & $\mathbf{f r \%}$ \\
\hline $\begin{array}{c}\text { Atributos } \\
\text { relacionados ao } \\
\text { conceito liderança }\end{array}$ & $\begin{array}{c}\text { "responsabilidade"; "importante pro cara } \text { desenvolver } \\
\text { aptidões"; "coordenação e desempenho"; "líder". }\end{array}$ & 04 & 30,77 \\
\hline $\begin{array}{c}\text { Atributos } \\
\text { relacionados à } \\
\text { função de comando }\end{array}$ & $\begin{array}{c}\text { "comando de pessoas"; "função de comando"; "liderar [...] } \\
\text { atingir objetivo comum"; "superior hierárquico". }\end{array}$ & 04 & 30,77 \\
\hline $\begin{array}{c}\text { Atributos da relação } \\
\text { Líder-Liderado }\end{array}$ & $\begin{array}{c}\text { confiança"(relacionado pelo entrevistado com a relação entre } \\
\text { as pessoas); "pessoa que dá o exemplo"; "liderança [...] } \\
\text { arrasta"; "exemplo"; "motivar [...] e confiar no potencial de } \\
\text { cada uma delas". }\end{array}$ & 05 & 38,46 \\
\hline
\end{tabular}

\begin{tabular}{|l|c|c|}
\hline Aspectos positivos quanto ao termo indutor: Liderança & 13 & 100 \\
\hline Aspectos negativos quanto ao termo indutor: Liderança & 00 & - \\
\hline
\end{tabular}




\section{TABELA 2 - Categorização das respostas dos participantes sobre a segunda pergunta}

Conteúdo da segunda pergunta pelo teste de associação de palavras: "Diga-me o que lhe vem à mente quando falamos sobre: Liderança no ambiente de trabalho"

\begin{tabular}{|c|c|c|c|}
\hline Categorias & Termos Respondidos pelos Entrevistados & fi & fr\% \\
\hline $\begin{array}{l}\text { Importância para } \\
\text { o meio militar }\end{array}$ & $\begin{array}{l}\text { "importante para manter a hierarquia e a disciplina"; } \\
\text { "importante, é um dos alicerces". }\end{array}$ & 02 & 15,39 \\
\hline $\begin{array}{c}\text { Atributos } \\
\text { relacionados ao } \\
\text { conceito liderança }\end{array}$ & $\begin{array}{l}\text { "confiança"(colocado pelo entrevistado como conceito); } \\
\text { "capacidade de coordenação"; "eficiência, eficácia e } \\
\text { efetividade"; "camaradagem"; "capacidade". }\end{array}$ & 05 & 38,46 \\
\hline $\begin{array}{l}\text { Atributos da } \\
\text { relação Líder- } \\
\text { Liderado }\end{array}$ & $\begin{array}{c}\text { "seguir par"; "pessoas que dá o exemplo"; "trazer a equipe } \\
\text { [...] para atingir o objetivo"; "lidar com o subordinado no } \\
\text { melhor ambiente possível"; "motivar [...] e confiar no } \\
\text { potencial de cada uma delas". }\end{array}$ & 05 & 38,46 \\
\hline $\begin{array}{l}\text { Relação com o } \\
\text { aprendizado da } \\
\text { liderança }\end{array}$ & "envolve conhecimento da sua função". & 01 & 7,69 \\
\hline
\end{tabular}

Aspectos positivos quanto ao termo indutor: Liderança no Ambiente de trabalho

Aspectos negativos quanto ao termo indutor: Liderança no Ambiente de trabalho

\section{TABELA 3 - Categorização das respostas dos participantes sobre a terceira pergunta}

Conteúdo da terceira pergunta pelo teste de associação de palavras: "Diga-me o que lhe vem à mente quando falamos sobre: Liderança na Administração Pública" "

\begin{tabular}{|c|c|c|c|}
\hline Categorias & Termos Respondidos pelos Entrevistados & $\mathbf{f i}$ & $\mathbf{f r} \%$ \\
\hline $\begin{array}{c}\text { Atributos } \\
\text { relacionados ao } \\
\text { conceito liderança }\end{array}$ & "legalidade"; "tem que ser transparente"; “autenticidade"; \\
"primar pela transparência". & 04 & 30,77 \\
$\begin{array}{c}\text { Atributos da } \\
\text { relação Líder- } \\
\text { Liderado }\end{array}$ & $\begin{array}{c}\text { "lidar com funcionários públicos"; "trazer a equipe, para } \\
\text { trabalhar em prol daqueles objetivos"; "trabalhar pro bem- } \\
\text { estar da população"; "confiar nos subordinados"; "lidar com } \\
\text { funcionários públicos". }\end{array}$ & 05 & 38,46 \\
\hline $\begin{array}{c}\text { Crítica à gestão da } \\
\text { liderança na Adm. } \\
\text { Pública }\end{array}$ & $\begin{array}{c}\text { "uma porcaria [...]"; "é ruim, muito o que melhorar ainda"; } \\
\text { "políticos agirem na forma correta"; "transparência, deveria } \\
\text { ser né!". }\end{array}$ & 04 & 30,77 \\
\hline
\end{tabular}

\begin{tabular}{|l|l|l|}
\hline Aspectos positivos quanto ao termo indutor: Liderança & 09 & 69,23 \\
\hline Aspectos negativos quanto ao termo indutor: Liderança & 04 & 30,77 \\
\hline
\end{tabular}

\subsection{Análises}

Conforme apresentado, foi possível classificar em categorias as respostas dos participantes. Em relação ao termo indutor "liderança" 38,46\% dos entrevistados referenciaram a respeito de algum atributo presente na relação líder e liderado, como a postura exemplar, a motivação para desempenhar os objetivos que é comumente tratado pela teoria da troca entre líderes e membros - LMX (Leader Member Exchange Theory), segundo especifica Brant (2012). Enquanto que 30,77\% trouxeram sobre atributos atinentes ao líder em si, comentados pela teoria dos traços, como: responsabilidade, coordenação, necessários a ação de liderar, fato em que Cunha y Silva (2010) colocam que esses traços são os determinantes de um líder dentro deste escopo 
teórico. Ainda, 30,77\% relataram que a liderança remete às questões de comandar, ou seja, fizeram menção a este tipo de ação de comando militar, pelo contexto em que vivem os entrevistados, sendo presente e permanente a relação hierárquica e disciplinar, fato que, com o advento da pergunta remeteram a própria cultura organizacional.

Também, em relação ao primeiro termo indutor, liderança, todos os participantes relacionaram suas respostas de maneira positiva, assim, em um processo de ancoragem do termo, conforme especifica Moscovici (2012), tornam comum o conceito de liderança relacionado a um material subjetivo que lhes trazem satisfação, remetendolhes a importância da liderança a algum meio social experenciado, sendo classificado pelo grupo dessa forma.

Em relação ao termo indutor: "liderança no ambiente de trabalho" 38,46\% dos entrevistados mencionaram em suas respostas atributos relacionados ao conceito de liderança, como eficiência e capacidade, semelhante ao verificado na primeira pergunta, que segundo Andrade (2013) trata-se de traços que remetem a um padrão básico de personalidade dos líderes pela visão da teoria dos traços. Também, houve 38,46\% que em suas respostas lhes remeteram a respeito da relação líder-liderado, uma relação dual, em que atributos como motivação e dar o exemplo fazem parte dessa subjetivação, o que demonstra a perspectiva subjetiva dos entrevistados ao tornarem comum tal conceito (Moscovici 2012). Também, 15,39\% mencionaram sobre a importância da liderança para o meio militar, ao pensarem sobre o ambiente de trabalho foi-lhes relevante falar sobre a importância para a manutenção do mesmo, o que vai ao encontro do mencionado por Cunha y Silva (2010) em relação da importância das ações de liderança quanto à possibilidade de vencer situações adversas e manter o potencial motivacional da equipe. E quanto ao restante dos entrevistados, foi respondido com relação ao aprendizado, sendo pertinente o conhecimento para a liderança no ambiente de trabalho.

Da mesma forma que no termo anterior, todos os participantes mencionaram aspectos positivos, havendo semelhança entre as respostas das duas primeiras perguntas, entretanto, com o presente termo indutor, quatro entrevistados, dos treze participantes apresentaram algum tipo de ansiedade ao falar sobre o tema, havendo por eles significativa demora em suas respostas, caso em que um dos entrevistados ficou ruborescido, por alguma associação subjetiva não manifesta que lhe remeteu forte ansiedade, sendo interrompida a entrevista até que se recuperasse e reinicia-se posteriormente. Além dos quatro participantes, outros dois em suas respostas repetiram a pergunta de modo a ganharem tempo e um terceiro murmurou em baixo volume após sua resposta uma exclamação de insegurança ao responder: “- num sei". Tal situação Merten (1992) menciona como tempo de reação no processo de associação, e quando ocorrem respostas retardadas, uma das hipóteses é o fato da palavra-estímulo ativar ideias com significados do ponto de vista emocional ao entrevistado.

Apesar disso, em um processo de ancoragem do termo (Moscovici 2012), mesmo com ansiedade manifesta de quatro participantes, devido algum intercurso vivido ou experienciado quanto ao conceito, as respostas trazidas tornam comum o conceito de liderança no ambiente de trabalho, relacionado a um material subjetivo positivo, remetendo-lhes a relevância da liderança para suas atividades, sendo classificado por eles como algo de reconhecida importância no exercício profissional, indo ao encontro do que Freitas (2013) aborda ao mencionar a relevância da liderança para o desenvolvimento de estratégias e qualidade dos serviços públicos. 
Em relação à terceira pergunta, cujo termo indutor foi: "liderança na Administração Pública" 38,46\% dos entrevistados responderam algo relacionado aos atributos da relação líder-liderado, em que visualizaram a ação de liderar na Administração Pública meio a uma relação social, como citado: "lidar com funcionários públicos", "confiar nos subordinados". Também, 30,77\% criticaram a gestão da liderança na Administração Pública, fato este que remeteu às suas experiências pessoais vividas, algo citado na presente pesquisa como deficitário e confirmado em prática pelos participantes que, em contrapartida, anteriormente mencionaram a respeito da importância da liderança. Os outros $30,77 \%$ responderam sobre atributos que constituem a liderança na Administração Pública, contudo, diferentemente dos outros termos indutores trabalhados, neste, os termos citados se referem mais a uma necessidade premente do que a constituição do conceito de liderar, sendo as respostas citadas "ser transparente", "legalidade", "primar pela transparência", "legalidade".

É importante mencionar que em relação às respostas, o presente termo indutor foi o que provocou maiores desconfortos aos entrevistados, cinco, dos treze da amostra, apresentaram dificuldades ao responder, em função de algum tipo de dificuldade pessoal presente, havendo significativo atraso nas respostas, haja vista que lhes foram instruídos a maneira de se responder utilizando-se da técnica de associação de palavras. Ainda, houve resistência em verbalizar, havendo dois entrevistados que acharam complicado responder ao termo indutor apresentado.

Em um processo de ancoragem do termo liderança na Administração Pública foi constatado para $30,77 \%$ dos entrevistados dificuldade em classificar o termo, havendo relevante crítica a Administração Pública quanto a não utilização dessa ferramenta de gestão, em torná-la comum, tendo em vista a deficitária utilização da liderança nesse meio, até mesmo pela pouca e recente atenção a essa necessidade nas políticas públicas, conforme apresentado por Martins y colaboradores (2010). Sendo distante o processo de objetivação (Moscovici 2012) da liderança na Administração Pública, pelo fato desse conceito estar muito abstrato até mesmo para os agentes públicos, necessitando de grande investimento para revertê-lo em algo concreto e familiar.

\section{Conclusão}

O presente estudo teve como objetivo o levantamento da Representação Social da Liderança junto aos agentes de uma Organização da Administração Pública Federal, de forma a verificar a relevância e importância da liderança no processo psicossocial do meio pesquisado.

O mesmo fora alcançado por meio da técnica de associação livre de palavras, apresentando-se termos indutores relacionados ao tema a uma amostra significativa, em que se pôde conhecer aspectos muito relevantes no que tange à liderança na gestão pública, com a utilização da análise de conteúdo para verificação dos dados obtidos.

Com a análise dos resultados verificou-se como representação social da amostra pesquisada a necessidade da liderança no meio estudado e sua consequente falha na gestão pública, haja vista, as respostas críticas trazidas pelos participantes da pesquisa. Algo relevante e significativo para o planejamento e gestão na unidade pesquisada, podendo contribuir para modificações fundamentais na estrutura da cultura organizacional presente. Sendo possível, também, verificar o quão necessário faz-se a liderança na administração pública, tanto nas questões atinentes à gestão quanto no desenvolvimento desse campo científico de conhecimento. 
Contudo, apesar da relevância trazida pelo estudo, a pesquisa abordou somente uma amostra pertencente a uma unidade da administração pública federal, além de se tratar de um trabalho de investigação qualitativo. Dessa maneira, torna-se necessário repensar pesquisas com escopo maiores, objetivando elucidar o tema em dimensões mais abrangentes.

Assim, pela relevância dada pelo grupo pesquisado sobre o tema, em análise da Representação Social encontrada, cresce a importância de futuras pesquisas sobre o assunto e a necessidade de um espaço legítimo na administração pública para o trato das questões relacionadas à liderança. Portanto, com o modelo de gestão societal e a necessidade encontrada, espera-se uma inversão do quadro apresentado, para que o subjetivo ganhe relevância nas ações públicas, neste caso, a liderança, pela possibilidade de influenciar o ambiente organizacional e social das pessoas, objetivando conquistas no convívio pessoal, familiar e profissional dos seus agentes, trazendo por consequência possíveis ganhos nos mais diversos setores e no desenvolvimento da ciência.

\section{Referências}

Almeida, A. M. O. (2009). Abordagem Societal das Representações Sociais. Sociedade e Estado, Brasília, 24 (3), 713-737.

Andrade, J.A., Muniz, I.S.A, \& Silva, C. A. da. (2010). Inovação e Representações Sociais de Dirigentes das Empresas de um Pólo Tecnológico. Contextus Revista Contemporânea de Economia e Gestão, Fortaleza, 8(2), 73-80.

Andrade, M. M. M. B. (2013). A Liderança em Contextos Organizacionais Competitivos, e de Elevada Complexidade: Estudo de Caso na Indústria Farmacêutica. Exedra Journal. Coimbra: Portugal, 8, 120-138.

Araújo, A. R. \& Zuppano, T. S. (2016). Potenciais Desafios para Líderes Contratados em Empresas Familiares de Pequeno Porte. Revista da Micro e Pequena Empresa, Campo Limpo Paulista, (10)1, 29-43.

Arengheri, M. (2014). O Estilo de Liderança do Gestor Escolar e a Motivação dos Professores. Revista Diálogos Interdisciplinares, São Paulo, Vol. 3, n. 1. ISSN 23173793.

Athaydes, A., Becker, G. H., Cogo, R. S., Furlanetto, M. \& Nassar, P. (2013) Estudo Transcultural sobre Liderança em Relações Públicas e Gestão da Comunicação: análise quantitativa dos temas de maior importância para os brasileiros. Revista Internacional de Relaciones Públicas, Málaga, 6 (3), 5-28.

Azevedo. D., Walber, A.L.S., Schujmann, A. \& Garay, A.B.S. (2012). Representações sociais de RH: um Estudo Exploratório com Alunos de Graduação. Revista Organizações e Sociedade, Salvador, 19(60), 51-66.

Bardin, L. (1977). Análise de Conteúdo. Tradução Luís Antero Reto e Augusto Pinheiro. São Paulo: Martins Fontes, 1977. (Tradução do original em língua francesa L'analyse de Contenu. Paris: P.U.F., 1977). 
Benevides, V. L. A. (2010). Os Estilos de Liderança e as Principais Táticas de Influência Utilizadas pelos Líderes Brasileiros. (Dissertação de Mestrado). Fundação Getúlio Vargas, Mestrado Executivo em Gestão Empresarial, Rio de Janeiro.

Bergamini, C. W. (1994). Liderança: A Administração do Sentido. (3a ed). São Paulo: Atlas.

Brant, P. S. (2012). A Relação entre Líderes e Membros (LMX), Estilos de Liderança e seus Impactos na Satisfação no Trabalho. (Dissertação de Mestrado). Universidade FUMEC/ FACE, Mestrado em Administração, Belo Horizonte.

Bresser-Pereira, L. C. (2001). Do estado patrimonial ao gerencial. In: Pinheiro, P. S.; Wilheim, J.; Sachs, I. (Org.). In: Brasil: um século de transformações. São Paulo: Companhia das Letras, 222-259.

Carbone, P. P. (2000). Cultura Organizacional do Setor Público Brasileiro: Desenvolvendo uma Metodologia de Gerenciamento da Cultura. Revista de Administração Pública, Rio de Janeiro, 34 (2), 133-144.

Carvalho, I. S. C. \& Souza, M. V. M. de. (2012). A Representação Social de Alunos de Escolas da Rede Particular de Ensino Acerca do Papel do Psicólogo Escolar. Trabalhos em Linguística Aplicada-Unicamp, Campinas, (51)1, 235-244.

Ceneviva, R. \& Farah, M. F. S. (2012). Avaliação, Informação e Responsabilização no Setor Público. Revista de Administração Pública, Rio de Janeiro, 46 (4), 993-1016.

Costa, F. L \& Costa, E. M. L. (2016). Nova história da administração pública brasileira: pressupostos teóricos e fontes alternativas. Revista de Administração Pública, Rio de Janeiro, 50(2), 215-236.

Cunha, C. V. M. \& Silva, M. J. M. C. A. (2010). Os Desafios da Liderança no Mundo Corporativo. Anuário da Produção Acadêmica Docente. Valinhos-SP: Faculdade Anhanguera de Taubaté, 4 (7), 67-88.

Drumond, A. M., Silveira, S. F. R. \& Silva, E. A. (2014). Predominância ou Coexistência? Modelos de Administração Pública Brasileira na Política Nacional de Habitação. Revista de Administração Pública, Rio de Janeiro, 48(1), 3-25.

Fadul, E. M. C., Silva, M. A. M. \& Silva, L. P. (2012). Ensaiando Interpretações e Estratégias para o Campo da Administração Pública no Brasil. Revista de Administração Pública, Rio de Janeiro, 46 (6), 1437-1458.

Ferreira, A. C., Santos, E. R. dos \& Rosso, A. J. (2016). Representação Social da Indisciplina Escolar. Psicologia: Teoria e Pesquisa, Brasília, (32) 1, 199-208.

Fonsêca, M. A. (2011). Bem-Estar Laboral e o Comprometimento Organizacional. (Monografia de Bacharelado em Administração). Universidade de Brasília, Brasília.

Fontanella, B. J. B., Ricas, J. \& Turato, E. R. (2008). Amostragem por Saturação em Pesquisas Qualitativas em Saúde: Contribuições Teóricas. Caderno de Saúde Pública, Rio de Janeiro, 24 (1), 17-27.

Freitas, A. F., Freitas, A. F. \& Ferreira, M. A. M. (2016). Gestão Social Como Projeto Político e Prática Discursiva. Cadernos EBAPE.BR - FGV, Rio de Janeiro, (14) 2, 281-292. 
Freitas, M. I. A. A. (2013). As Tecnologias de Informação e da Comunicação como Suporte à Gestão Através da Liderança e da Comunicação: Estudo com Professores de um Agrupamento de Escolas da Terra Fria Transmontana. (Dissertação de Mestrado). Instituto Politécnico de Bragança, Mestrado em Ciências da Educação, Bragança-SP.

Gil, A. C. (2007). Como Elaborar Projetos de Pesquisa. (4a ed). São Paulo: Atlas.

Gonçalves, L. C. C. (2014). Estilo de Liderança e Papel de Coordenador do CAP na Motivação da sua Equipa. (Dissertação de Mestrado). Universidade da Madeira, Mestrado em Ciências da Educação, Funchal: Portugal.

Janczura, G. A. (2005). Contexto e Normas para Associação para Palavras: A Redução para o Campo Semântico. Paideia, Ribeirão Preto, 15 (32), 417-425.

Jodelet, D. (2001). Representações Sociais: Um Domínio em Expansão. In: Jodelet, D. (Org.). As Representações Sociais (pp. 17-44). Rio de Janeiro: UERJ; 2001.

Jodelet, D. (2009). O Movimento de Retorno ao Sujeito e a Abordagem das Representações Sociais. Sociedade e Estado, 24(3), 679-712.

Lemos, S. F. C., Costa, S. G. \& Lima, R. C. P. (2013). Representações Sociais: Aplicabilidade nos Estudos sobre a Educação de Jovens e Adultos. Educação, Sociedade e Culturas, Rio de Janeiro, 39, 43-61.

Martins, B. V., Marques, J. R., Vieira, L. J. M. \& Garay, A. B. S. (2010) Avaliação de Desempenho Individual no Setor Público Brasileiro: Análise da Produção Acadêmica de 2000 a 2009. In: IV Encontro de Administração Pública e Governança da $A N P A D$. Anais IV da EnAPG, Vitória-ES.

Merten, T. (1992). O Teste de Associação de Palavras na Psicologia e Psiquiatria: História, Método e Resultados. Lisboa: Portugal: Instituto Superior de Psicologia Aplicada - Análise Psicológica, 10(4), 531-541.

Moraes, R. (1999). Análise de conteúdo. Revista Educação, Porto Alegre, 22 (37), 7-32.

Moscovici, S. (2012). Representações Sociais: Investigações em Psicologia Social. Tradução Pedrinho Arcides Guareschi. (9a ed). Petrópolis, RJ: Vozes.

Natividade, J. C., \& Camargo, B. V. (2012). Elementos da Representação Social da AIDS Agrupados em Dimensões: Uma Técnica Estrutural. Psicologia: Teoria e Pesquisa, 28(2), 193-195.

Niemeyer, J. R. L. \& Cavazotte, F. S. C. N. (2016). Ethical Leadership, LeaderFollower Relationship and Performance: A Study in a Telecommunications. Revista de Administração Mackenzie-RAM, São Paulo, 17(2), 67-92.

Oliveira, F. B., Sant'anna, A. S. \& Vaz, S. L. (2010). Liderança no Contexto da Nova Administração Pública: Uma Análise sob a Perspectiva de Gestores Públicos de Minas Gerais e Rio de Janeiro. Revista de Administração Pública, Rio de Janeiro, 44 (6), 1453-1475.

Oliveira, J. C. \& Chamarelli, J. (2011). Liderança Situacional: Eficácia da Liderança do Gestor de Recursos Humanos. Revista Cognitio, Lins-SP. 
Oliveira, V. C. S. \& Pereira, J. R. (2014). Sociedade, Estado e Administração Pública: Análise da Configuração Institucional dos Conselhos Gestores do Município de Lavras (MG). Cadernos Gestão Pública e Cidadania, São Paulo, (19)64, 19-40.

Paula, A. P. P. de (2005). Administração Pública Brasileira Entre o Gerencialismo e a Gestão Social. RAE-Revista de Administração de Empresas, (45)1, 36-49.

Pfeffer, J. (2015). Leadership BS: Fixing Workplaces and Careers One Truth at a Time. HarperCollins.

Pope, C \& Mays, N. (2009). Pesquisa Qualitativa na Atenção à Saúde. (3a ed). Porto Alegre: Artmed.

Resolução $n^{\circ}$ 196, de 10 de outubro de 1996, versão 2012. (2012). Diretrizes e Normas Regulamentadoras de Pesquisas Envolvendo Seres Humanos. Ministério da SaúdeConselho Nacional de Saúde, Brasília, DF: CNS. Consultado em 20 de março de 2014, através de http://conselho.saude.gov.br/web_comissoes/conep/arquivos/resolucoes/ 23_out_ versao_final_196_ENCEP2012.pdf.

Resolução $n^{o}$ 466, de 12 de outubro de 2012. (2012). Dispõe sobre as Diretrizes e Normas Regulamentadoras de Pesquisas Envolvendo Seres Humanos. Ministério da Saúde-Conselho Nacional de Saúde, Brasília: CNS. Consultado em 20 de março de 2014, através de http://conselho.saude.gov.br/resolucoes/2012/Reso466.pdf.

Rowe, W. G. (2002). Liderança Estratégica e Criação de Valor. Revista de Administração de Empresas, São Paulo, 42(1), 7-19.

Santana, G. A. S., Reis, A. O., Reis, M. C. T. \& Tavares, B. (2013). A Representação Social na Interpretação de um Sonho de Cidade Coletivamente Construído. APGSAdministração Pública e Gestão Social, Viçosa, (5)1, 41-55.

Schette, F. R. (2005). O Papel da Psicologia no Desenvolvimento de Líderes Organizacionais Segundo Psicólogos e Líderes. (Tese de Doutorado). Pontifícia Universidade Católica, Programa de Pós-Graduação em Psicologia - Centro de Ciências da Vida, Campinas-SP.

Silva, E. L. \& Menezes, E. M. (2005). Metodologia da pesquisa e elaboração de dissertação. (4a ed). Florianópolis: UFSC, 138 p.

Tenório, F. G. (1998). Gestão Social: Uma Perspectiva Conceitual. Revista de Administração Pública - RAP / EBAPE / FGV, (32)5, 7-23.

Tenório, F. G. (2005). (Re)visitando o Conceito de Gestão Social. In: Lianza, S. \& Addor, F. Tecnologia e Desenvolvimento Social e Solidário. Porto Alegre, UFRGS, 151-171.

Vieira, L. J. M. V. \& Costa, S. G. (2013). Liderança no Judiciário: O Reconhecimento de Magistrados como Líderes. Revista de Administração Pública, Rio de Janeiro, 47 (4), 927-948.

Vils, L. \& Rodrigues, G. V. (2016). Leadership B.S.- Jefrey Pfeffer e a Indústria da Liderança. Revista Ibero-Americana de Estratégia-RIAE, São Paulo, (15)1, 147-154. 